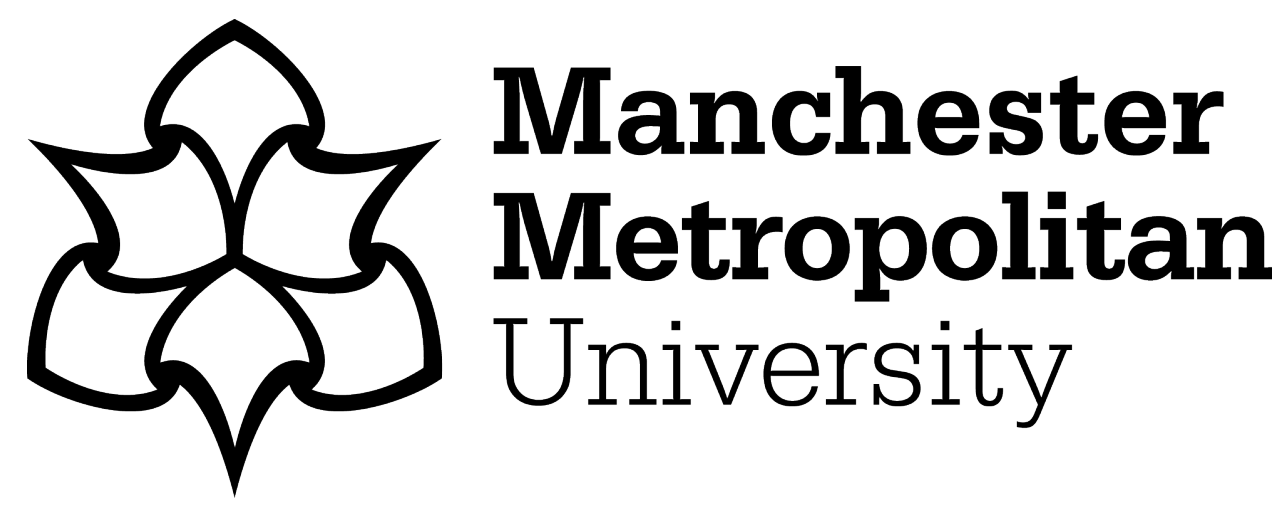

Powell, Stephen ORCID logoORCID: https://orcid.org/0000-00033906-5867, Prowse, Alicia and McCabe, Orlagh ORCID logoORCID: https://orcid.org/0000-0002-1095-513X (2020) Problem Structuring for Future University Learning. In: 14th International Technology, Education and Development Conference, 02 March 2020 - 04 March 2020, Valencia, Spain.

Downloaded from: https://e-space.mmu.ac.uk/626717/

Version: Accepted Version

Publisher: IATED Academy

DOI: https://doi.org/10.21125/inted.2020.0446

Please cite the published version 


\title{
PROBLEM STRUCTURING FOR FUTURE UNIVERSITY LEARNING
}

\author{
Stephen Powell ${ }^{1}$, Alicia Prowse ${ }^{2}$ [Orlagh McCabe ${ }^{3}$ \\ ${ }^{1-3}$ Manchester Metropolitan University (UK)
}

\begin{abstract}
This study was undertaken as part of a UK government funded project to develop new approaches to personalised learning. Part of this work involved using Rich Pictures, a problem structuring inquiry technique used in Soft Systems Methodology to identify "the main entities, structures and viewpoints in the situation, the processes going on, the current recognised issues and any potential ones" [1]. In this case, the problematical situation being future learning in universities and how to better organise it so that it is personalised to the needs of learners with the use of technology being a key enabler in moving away from traditional approaches to teaching and learning. The research revealed that on the one hand, students valued highly the face-to-face interaction provided by a physical campus that seemed to afford opportunities for engagement not just with course-related content but sports and friendships. Competing with this, students identified significant financial and time pressures they experienced when attending university and reported this to be a significant barrier to attendance and participation, and a significant cause of distress. On first consideration, technology would seem to provide an obvious solution to the challenge of attendance at a particular place and time, however students did not universally welcome this proposition and in this paper, we explore this dichotomy.
\end{abstract}

Keywords: Soft Systems Methodology, problem structuring, online distance learning

\section{INTRODUCTION}

Universities in the UK have existed since the 1300s. The expansion of the sector during the latter part of the twentieth century has largely continued in the same mould that has existed during previous centuries. This is a model of master - apprentice where the apprentice 'sits at the feet of the master' to learn. Re-imagining the university may necessitate an escape from the traditional model although this can be difficult to do when we are encultured in the systems and processes that sustain these institutions. We identify this as a significant issue in our context as, arguably, the existing university system is designed around the convenience of the institution and its lecturers, rather than the learners, and that as model is becoming increasingly unsustainable. We observe this tension through challenges with student attendance at university, their need to work to fund their studies, and the increasing complexity and deterioration of the boundaries between work, study and leisure brought about through the evolution of technology. We see that a change is desirable towards a university system with flexibility and personalisation to individual needs and wants and that this change in capabilities, both institutional and individual, can only be brought about by the increased use of technology.

\section{BACKGROUND}

Technology has promised much in this respect since the late 1990's by way of Online Distance Learning (ODL), but delivered disappointingly little in terms of systemic changes in the way that we provide higher education. Over the years there have been national and international peaks of excitement that a new day is dawning for ODL. For example, optimism over the UK eUniversity in the early 2000's, a £62 million pound venture that turned into disappointment after the negative publicity surrounding its failure and the impact of discouraging other institutions from trying to develop wholly online course [2]. More recently, the froth of optimism brought about by MOOC's and their open education model, threatening the possibility of developing new business models that could disrupt established Higher Education Institutions [3]. However, the available data in 2018 suggest that, at best, the growth in ODL has paused recently at relatively modest levels in terms of overall university provision and it may actually be in decline [4].

Over the same 20 year period outlined above, other significant changes that would logically have made possible the growth in ODL include the rapid takeup of technology and mobile learning to the extent to which it is now largely a ubiquitous service across the globe. Other trends in HE that would 
seem to favour the growth of ODL include: globalisation of education; the worldwide growth in demand for higher education; and the changing demographics leading to more adult learners [5]. However, there are also exceptions where examples of particular ODL programmes have tapped into the needs of specific learners who, for whatever reason, are unable to take advantage of existing face-to-face provision possibly because of work or family commitments. In these cases, particular pedagogical and organisational approaches can make higher education a possibility, for example the Ultraversity project a personalised educational experience designed for online distance learners who had to continue to work full time and study at a full time rate through learning about and improve the work that they were doing [6].

Given this background, the researchers were interested to explore how do learners learn in the real world and what insights might we gain about how to design learning systems in universities that meet the needs of learners and take full advantage of the opportunities that communication technologies provides.

\section{METHODS}

For this study, twenty students (aged 18-24; recruited and paid via the university 'jobs for students' department) participated in two focus groups (ten students in each). Each group participated in a 2 hour focus group/workshop with refreshments. First, they were introduced to the rich picture technique [1].

The first group was asked to explore future learning in universities using stimulus questions:

- what is rewarding \& enjoyable, and annoying \& disagreeable about your experience of university?

- what would university look like if we designed it for students?

The second group (two weeks later) were additionally asked to consider, as individuals:

- how 'they live and learn in the real world'.

This was followed by an exercise in pairs or small groups where they were asked to consider:

- having thought about living and learning in the real world, 'how would you design a 'university' experience'.

Students in the second group were asked to (individually) draw themselves living and learning in the 'real world'. This was in order to prepare the students to think as broadly as possible about their conception of learning within their own context and the other demands on their time that come from just 'living' (for example, paid work, care responsibilities, family time). In pairs or small groups, they were asked how they would design a 'university' experience and to draw this in the form of a rich picture. Contemporaneous field notes were also taken in the focus groups by one of the researchers, as students explained their pictures to the group. The resulting rich pictures and collated field notes were analysed using NVivo 12 and open coding to explore the outcomes. The two researchers reflected on observations made on the discussions immediately following the focus groups. A record of these observations were taken.

\section{FINDINGS}

Findings revealed for these students a tension between the two sets of competing desires. In the pictures of learning and living in the real world and students' narrations in relation to these, students talked about their 'natural' learning occurring in a holistic environment that included many aspects of wellbeing: good sleep, time to relax, time to be alone, and time to enjoy the company of others especially friends and family Fig. 1 and 2). They reported using many 'media / communication technologies' such as smartphones, YouTube platforms, film and TV, music, books and 'the internet' from which they learned about the world'; about the 'different viewpoints' of others; and particularly, how to relate to others. They were also very aware of how learning from others was a key part of the experience, via conversation and relationships with co-workers, friends and family.

'First way of learning is having conversations with other people, There is always someone more experienced and you need to find out what... going back and reflecting looking at different platforms... like social media and books and things like that' (focus group student). 


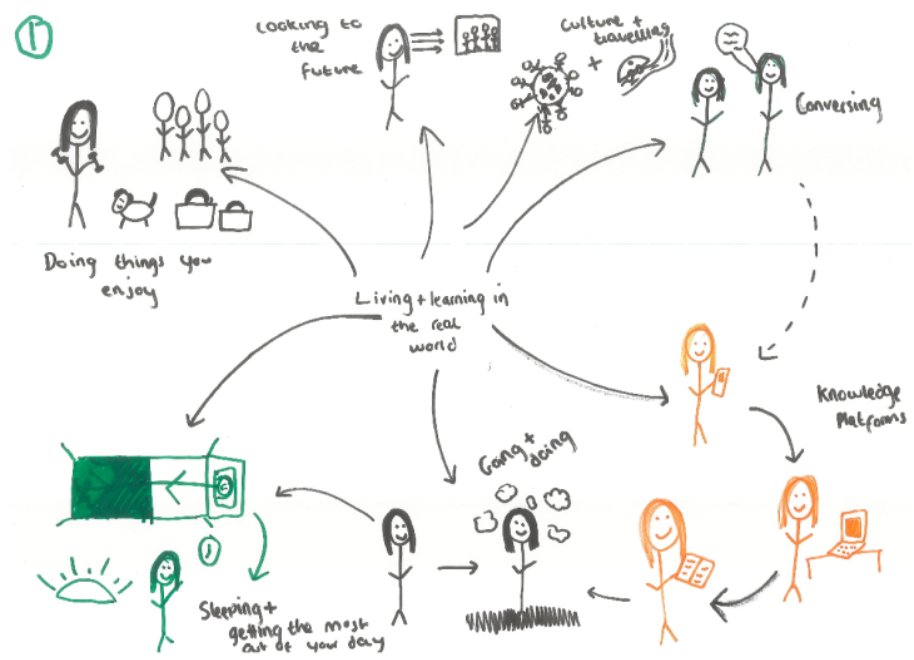

Figure 1. Student rich picture of living and learning in the real world (example 1).

Wellbeing and particularly the concept of enjoyment, emerged strongly as part of the essential environment for learning.

'Things you enjoy like being active and being with family and friends. Having a vision of what you want to do in the future and... You got to have time to yourself and you don't get stressed, you enjoy what you are doing....' (focus group student).

Students' positive vision of themselves in a future-facing outlook within a limited time frame also emerged strongly, with a clear belief that getting a good degree was important. Students acknowledged that their lives may take place in a 'protective bubble' but that they had a responsibility to look after their own wellbeing while also acknowledging reliance on family to provide a supportive base.

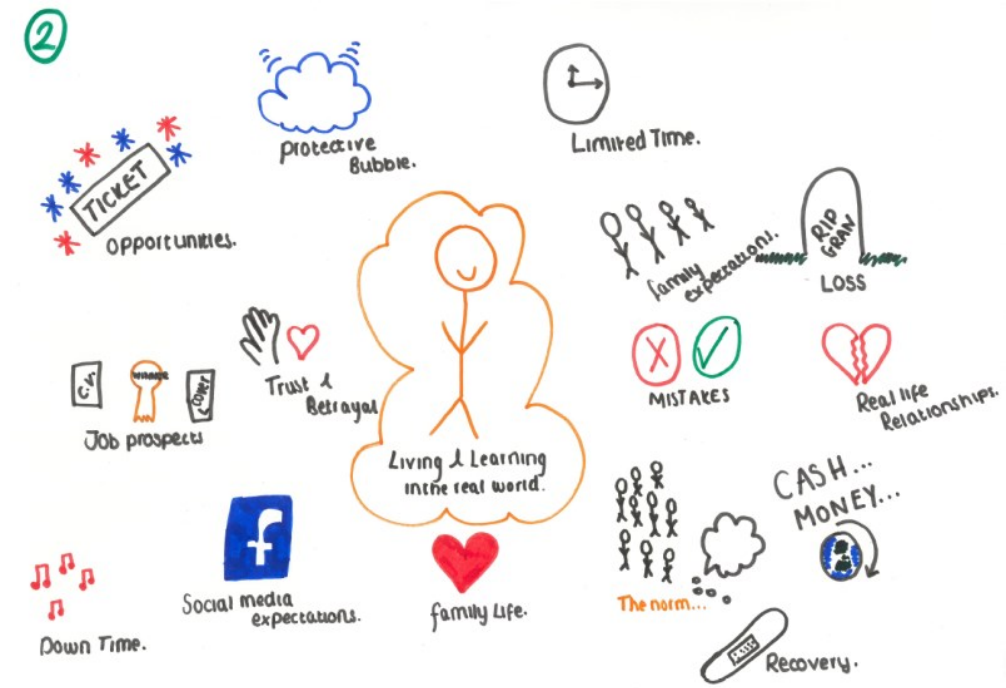

Figure 2. Student rich picture of living and learning in the real world (example 2).

....down time is essential to learning... Living with family is key to who you will become...values, what values you grow up with..you learn from the mistakes you make...life and loss...you have limited time on this planet.' (focus group student).

When students turned their attention to how to design learning for a new kind of university (Figure 3), they focussed strongly on social learning, work related learning and financial considerations. Media technologies featured largely in the idea of lecture capture (capturing a very traditional learning event, 
that was clearly seen as an enduringly key element of a university education) and communication methods, such as social media.

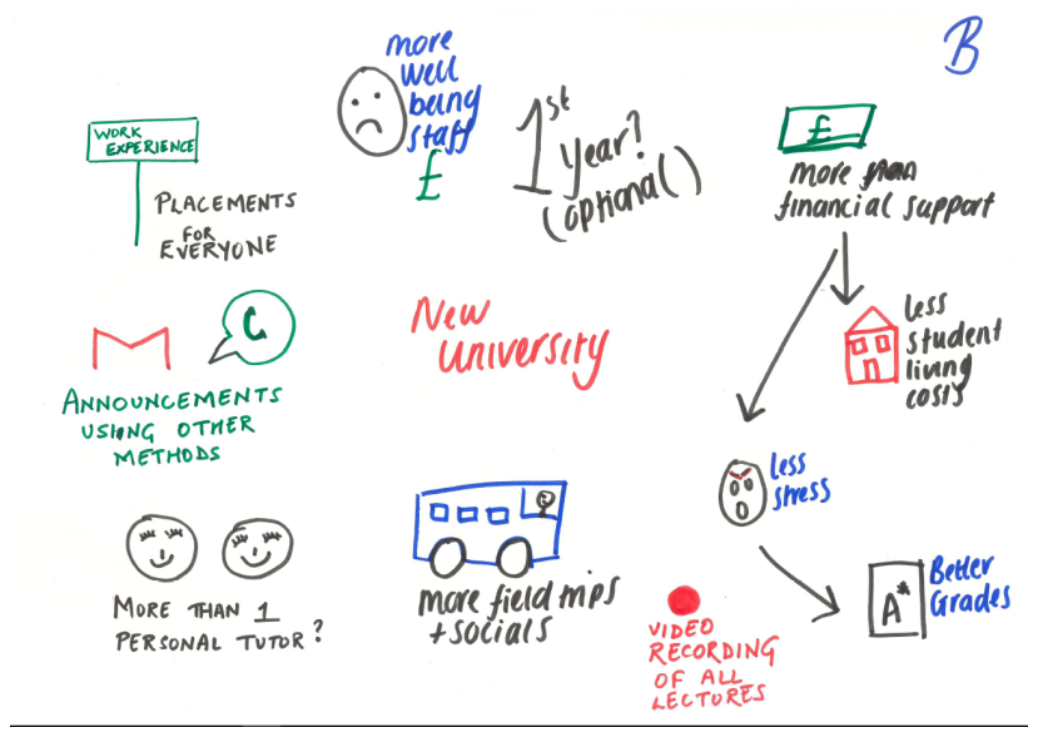

Figure 3. Student drawing of vision of a new kind of university.

Besides the idea of lecture capture, there was some appetite for ODL itself but this was only expressed by one student.

'There should be more distance learning. If you are on your own its hard to focus... because there are distractions... in the IT zone [in the university library]. Too many people and all not doing stuff.' (focus group student).

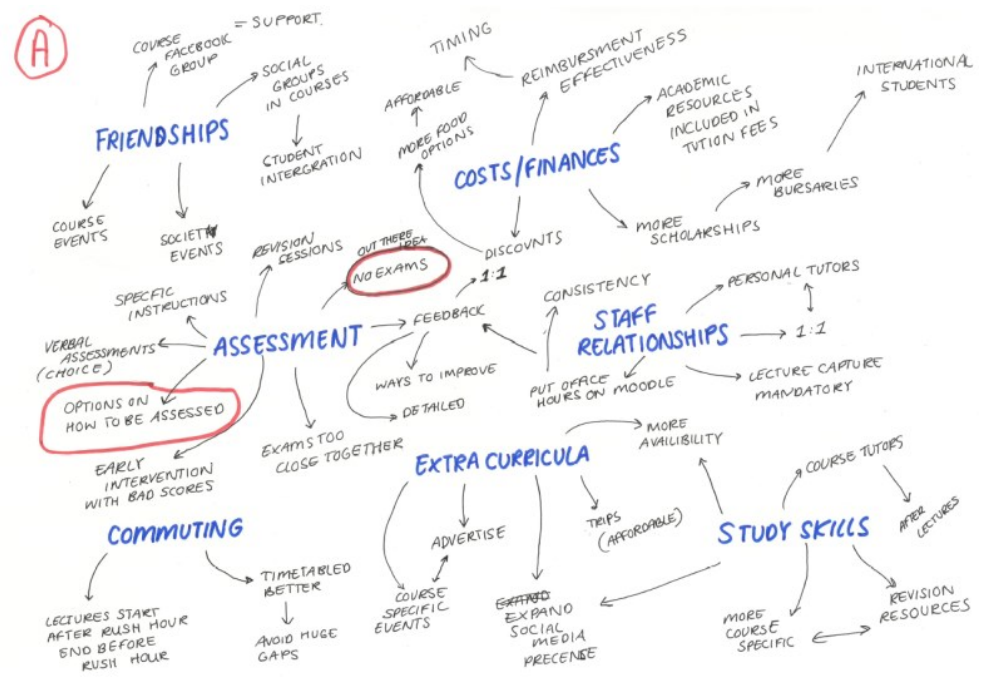

Figure 4. Student drawing of vision of a new kind of university.

We found ourselves surprised at the relatively conservative response to the idea of imagining a different kind of university. There was strong identification with social learning, dealing with the idea of commuting (though not necessarily invoking a technological solution to this) and an emphasis on financial solutions and ways of assessing that were less pressured. Communication via social media and resource availability were seen as the main ways in which technology could be useful but there was little appetite to dispense with a traditional model of attendance although an increased flexibility in this was suggested by several students. Students saw their attendance as not just based around their learning, but also on their social and sport or extra-curricular activity. 


\section{DISCUSSION}

One interpretation of the responses from students that attended our focus groups is that there is an element of confusion. For example, they want lecture capture so that they can view and review lecturers at a time and place that is convenient to them, but they do not want to stay at home and use lecture capture to get a degree. They want more contact from their tutors, but do not want to attend when they are scheduled to do so. University is too expensive now, but they want more of it.

The students in the focus groups did, however, also provide some useful starting points for the design of a higher education experience that puts at a premium a personalised experience. Not surprisingly, the students know they want a good degree. Fluent as they are in using technology for learning from a wide variety of sources and in different ways, they value very highly face-to-face interaction provided by a physical campus, not simply course related, but for developing friendships and participating in leisure activities.

One way of expressing these tensions is presented in fig. 5 Scenarios of Study. We have identified two dimensions, that of mode of study either face-to-face and personal constraints. Mode of study is relatively straight forward, although as well as the opposites of synchronous face-to-face and ODL, there are clearly blended modes of study also with varying proportions of each of the afore mentioned. Perhaps more complex is the dimension of personal constraints, as it encompasses a complex mix of elements. For example, distance to travel linked to financial cost and time. Family circumstances, such as caring responsibilities or the need to generate additional income through work commitments. Perhaps specific learning difficulties may be a significant constraint or personalities that prefer not to learn or work with others.

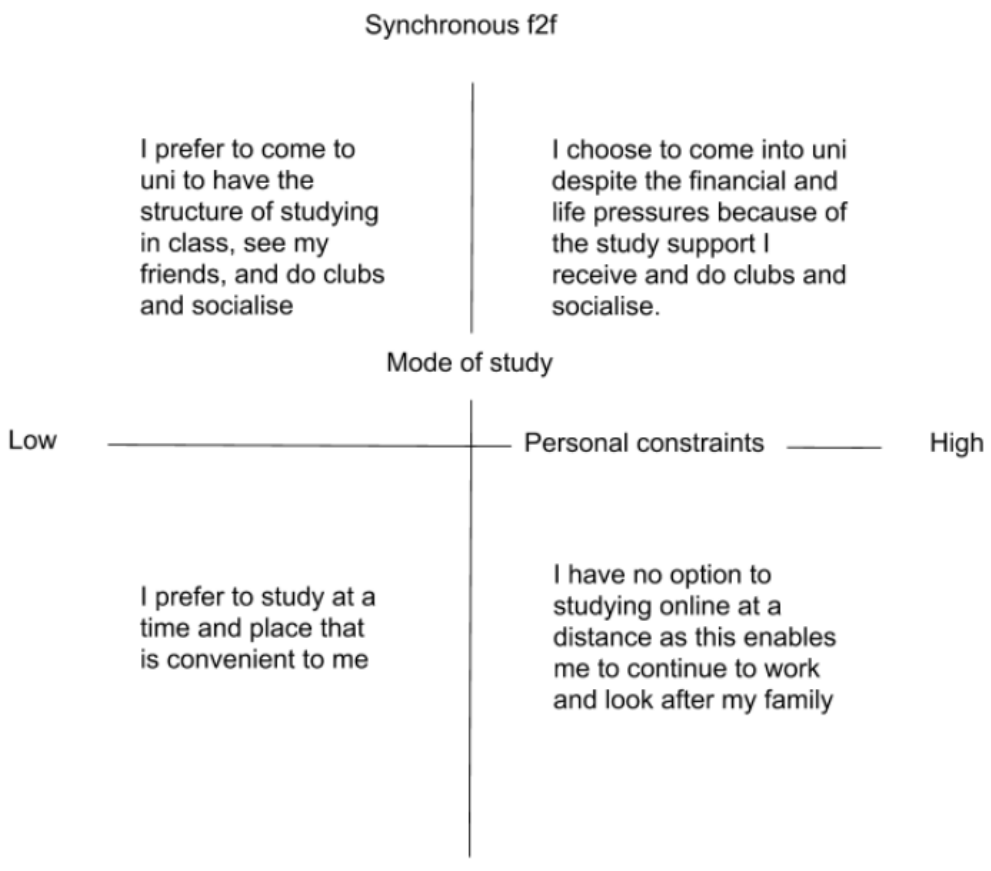

Asynchronous ODL

Figure 5. Scenarios of Study.

An alternative motivational dimension that could be overlaid with personal constraints is the extent to which a curriculum, in the broadest sense of the word, is annoying and disagreeable, or rewarding and enjoyable. Exploring questions like this is important as, over time, individuals circumstances will change and ensuring that through different levels of motivation and personal constraints it is still possible to achieve well on a programme of study. 


\section{CONCLUSIONS}

For designers of Higher Education experiences, it is important to recognise the different wants and persuasions of students. It is probably the case that seeing students as a homogeneous group is at the root of many of the challenges we face around attendance and student progression. It is also important to recognise that motivational factors will significantly impact on students levels of participation and engagement, but through good design we can develop curricula that meet the needs of different students and the same students as their constraints change over time through providing different ways to engage in their programmes of study.

\section{ACKNOWLEDGEMENTS}

Work funded by the Higher Education Funding Council for England (ref L09)

\section{REFERENCES [ARIAL, 12-POINT, BOLD, LEFT ALIGNMENT]}

References [Arial, 10-point, left alignment, upper and lower case] should be cited according to the Bibliography and Citation Style https://iated.org/citation_guide

[1] P. Checkland, and J. Poulter, Learning for Action: A Short Definitive Account of Soft Systems Methodology, and its use for Practitioners, Teachers and Students. Chichester: John Wiley \& Sons, 2006.

[2] R. Middlehurst, and S. Woodford, " Responding to the internationalisation agenda: Implications for institutional strategy ", Higher Education Academy Research Report, 2007.

[3] L. Yuan band S. Powell, "MOOCs and Disruptive Innovation: Implications for Higher Education”, eLearning Papers (33): pp. 1-8, 2013

[4] The Observatory on Borderless Education, "Whatever happened to the promises of online learning ? Lessons from Country Case Studies." The Observatory on Borderless Education, 2018.

[5] L. Yuan and S. Powell, "MOOCs and Open Education : Implications for Higher Education A white paper", JISC CETIS, 2013.

[6] S, Powell, I. Tindal and R, Millwood, "Personalized learning and the Ultraversity experience", Interactive Learning Environments, 16(1), 2008. 